\title{
BEHAVIOR OF WORK HARDENED SnPb-SOLDER AFFECTED COPPER ON CORROSION RESISTANCE IN pH VARIED ENVIRONMENTS
}

\author{
Muzibur M. RAHMAN ${ }^{1,2, *}$, Reaz S. AHMED ${ }^{1}$, Salim M. KAISER $^{3}$ \\ ${ }^{1}$ Department of Mechanical Engineering, Bangladesh University of Engineering and Technology, Dhaka-1000, Bangladesh \\ ${ }^{2}$ Department of Naval Architecture \& Marine Engineering, Military Institute of Science and Technology, Dhaka-1216, Bangladesh \\ ${ }^{3}$ Directorate of Advisory, Extension and Research Services, Bangladesh University of Engineering and Technology, \\ Dhaka-1000, Bangladesh
}

\begin{abstract}
Copper based materials are widely used in industrial and marine applications due to good mechanical properties and high corrosion resistant behavior. But the corrosion immunity varies for the variation of environmental factors. Moreover, alloying elements can have role on corrosion behavior, especially if it occurs through inclusion of $\mathrm{Sn-Pb}$ solder for repair works and environmental effects due to ageing. The present paper is an attempt to characterize the corrosion immunity level of copper after inclusion of tiny SnPb-solder material and work hardening in $\mathrm{pH}$ varied fresh water environments from $\mathrm{pH} 1$ to $\mathrm{pH} 13$ using gravimetric analysis, conductivity investigation and micrograph observation using optical as well as field emission scanning electronic microscope. The result reveals that solder material inclusion has increased the corrosion rate by about $14 \%$ in 30 days immersion in $\mathrm{pH}$ varied environments.
\end{abstract}

Keywords: Corrosion; Work hardening; SnPb-Solder inclusion; Copper; pH varied environment.

\section{Introduction}

Copper and copper alloys are widely used in industrial and marine applications as heat exchangers, pumps, valves, fasteners, bushes, bearings, pipelines and conductors in electrical systems due to many factors including high level of conductivity, mechanical strength, machinability and corrosion resistant behavior. With the rapid scientific and technological advancement as well as economic development, the requirement of copper is increasing continuously $[1,2]$. To meet the extensive demand of copper materials, it is an important issue to get copper from old products/items considering the depletion level of copper ores in the nature [3]. After a long span of operational life, there are two options with waste electrical and electronic equipment (WEEE), i.e., either recycling of copper through a rigorous extraction process or reusing the scrape materials at their leftover state for suitable engineering applications. Recycling is very difficult and costly affairs but preferred for regaining the properties as close to original state. On the other hand, reusing is very cheap but properties are yet to be predicted and suitable engineering applications are also to be explored [4-6].

If the second option is chosen, characterization of old copper in respect of different properties is a mandatory issue based on rehabilitation concept of waste copper items. In this regard, corrosion behavior of old copper remains a concern because of generally considered immunity of copper from corrosion due to its affiliation with novel metals in the periodic table. Its corrosion immunity is also based on a postulation on the existence of native copper in the earth's crust [1]. In the atmosphere, a very thin layer of brownish-green or greenish-blue in color 
known as patina is formed [7,8]. Established patina becomes stable and remains as a permanent part of the copper object in the atmosphere. Examples of the corrosion resistance of copper materials are artifacts that have been found in nearly pristine condition after having been buried in the earth for thousands of years, and copper roofing in rural atmospheres has been found to corrode at rates of less than $0.4 \mathrm{~mm}$ in 200 years [1,9]. But, in contact of water, copper corrodes due to number of factors as considered differently by different researchers [10-18]. According to a group of researchers [10-16], the oxygen is consumed through hydrogen-oxygen reaction and the hydrogen is coming out from the reaction of copper with water. It is considered that the hydrogen-oxygen reaction is faster than the formation rate of the atomic hydrogen from the corrosion reaction itself on copper. Moreover, it is not possible to detect the hydrogen released from copper as long as the supply rate of oxygen to the surface exceeds the rate of hydrogen generation, which results in erroneous consideration that copper is fully corrosion resistant. On the other hand, few researchers $[17,18]$ have expressed the disagreement on the corrosiveness of copper in pure water. However, the reaction rate varies with the variation of $\mathrm{pH}$ values, temperature and presence of other particles at the reaction region [19-22]. In addition, copper materials also show specific corrosion manifestations in the form of inter-crystalline corrosion and corrosion cracking [23].

Since, old copper wires and machine parts coming out from different sectors, such as, buildings, industries and ship breakings are many-a-times found to contain a little amount of solder materials comprised of lead, tin, silver, etc. Inclusion of such soldering materials in copper might be of very little amount, but its effect on the corrosion resistance may not be negligible. It is because the addition of alloying elements in copper has some role in corrosion behavior of the alloys being produced [24,25]. Moreover, old copper might have undergone work hardening over the long span of life due to operational and environmental conditions, which can have an influence on the corrosion behavior of metals and alloys [26]. Again, the corrosion of copper in a wide variety of media has remained a great concern to be examined, which have also been conferred by number of researchers through their works $[9,16,18,27,28]$. Considering the inclusion of $\mathrm{SnPb}$ solder in copper over a long period of useful life as electric wires or machine parts, this paper is an effort to investigate the corrosion behavior of naturally developed work hardened high copper alloy ( $\mathrm{Cu}-\mathrm{Sn}-\mathrm{Pb}$ alloy) to look for their suitable rehabilitations.

\section{Materials and Methods}

\section{Sample Preparation}

Copper wires and machine parts after extensive age of about five decades were taken as the material of focus to carry out the study. It was found that the collected old copper based material contains a little percentage of lead and tin. To ascertain the influence of these tin and lead individually on the corrosive properties of copper wires and machine parts, three more combinations of copper based materials were selected as to supporting the focused solder affected material. These additional sample materials were pure copper named as material-I, copper-tin alloy named as material-II and copper-lead alloy named as material-III. The SnPb-solder affected copper, i.e., material of focus under study, was named as material-IV. Material-I was collected as bulk copper ingots. Materials-II and material-III were developed through casting where tin and lead were taken as of similar amount found available in material-IV. Table 1 presents the chemical compositions of the four types of sample materials.

From the each type of materials, flat bars of size $300 \times 15 \times 12 \mathrm{~mm}$ were made through cutting and machining precisely keeping the effect on surface/edge grains minimal. The flat bars were at first homogenized for eight hours at a temperature of $500^{\circ} \mathrm{C}$ for the reduction of chemical segregation as well as grain size refinement and then solution treated for two hours at a temperature of $700^{\circ} \mathrm{C}$ to improve their workability. 
Table 1. Chemical composition of sample materials (mass fraction \%)

\begin{tabular}{cllcc}
\hline Elements & $\begin{array}{c}\text { Material-I } \\
\text { (Pure Cu) }\end{array}$ & $\begin{array}{c}\text { Material-II } \\
\text { (Cu-Sn Alloy) }\end{array}$ & $\begin{array}{c}\text { Material-III } \\
(\text { Cu-Pb Alloy) }\end{array}$ & $\begin{array}{c}\text { Material-IV } \\
\text { (Cu-Sn-Pb Alloy) }\end{array}$ \\
\hline $\mathrm{Cu}$ & 99.6298 & 98.4555 & 97.6570 & 97.1132 \\
$\mathrm{Sn}$ & - & 1.1335 & - & 1.2572 \\
$\mathrm{~Pb}$ & - & - & 1.9737 & 1.1949 \\
$\mathrm{Si}$ & 0.1372 & 0.1415 & 0.1129 & 0.1726 \\
$\mathrm{P}$ & 0.2330 & 0.2695 & 0.2564 & 0.2621 \\
\hline
\end{tabular}

Thereafter, work hardening was done using roller machine operated at room temperature by reducing the thickness of $75 \%$. To carry out such reduction of thickness, roller was operated at the lowest possible speed and only about $0.1 \mathrm{~mm}$ feed was applied for each roll pass so that the normal temperature could be maintained for desired work hardening of all four sample materials.

\section{Experimental Investigation}

All the four groups of samples were sized up such that they are suitable to carry out the examinations of corrosion behavior along with the observation of conductivity and microstructure. To carry out corrosion tests, coupons of $56 \mathrm{~mm}$ x $15 \mathrm{~mm}$ x $3 \mathrm{~mm}$ size were made following the ASTM G4 guide line and mechanically ground with 160, 300, 600, 900 and 1200 grits of SiC emery paper successively. On completion of dry grinding, all the samples were wet polished using alumina paste and dried up through air blow at room temperature. Then the metallographic images were observed using optical electronic microscope (OEM) with the magnification factors of 100x, 180x and 300x.

The electrical conductivity values of the samples were measured using Type 979 Meter with an accuracy of $\pm 0.1 \%$ IACS (International Annealed Copper Standard). At this stage, the samples were weighed in a high precision digital weighing machine to get the initial weight before their immersion in the stagnant solution of wide ranging variation of $\mathrm{pH}$ values $(\mathrm{pH} 1$ to $\mathrm{pH} 13)$ for corrosion test. Solutions of $\mathrm{pH} 1, \mathrm{pH} 3$ and $\mathrm{pH} 5$ were prepared by adding $10 \mathrm{~N} \mathrm{HCl}$ of $20 \mathrm{~mL}$, $0.2 \mathrm{~mL}$ and $0.002 \mathrm{~mL}$ respectively into $2000 \mathrm{~mL}$ of distilled water having $\mathrm{pH}$ level of 7 . On the other hand, the solutions of $\mathrm{pH} 9, \mathrm{pH} 11$, and $\mathrm{pH} 13$ were prepared by adding $1 \mathrm{~N} \mathrm{NaOH}$ of 0.02 $\mathrm{mL}, 2 \mathrm{~mL}$ and $200 \mathrm{~mL}$ respectively into $2000 \mathrm{~mL}$ of the same distilled water. The solution was used for the corrosion test at room temperature i.e $25^{\circ} \mathrm{C}$. After the exposure for a designated period in the solution medium, the samples were taken off, cleaned with distilled water and dried up naturally keeping on absorbent papers. The first experimental reading was taken after one day (24 hours) exposure of samples in solutions. Here, weight loss and conductivity variation of the samples were determined, and OEM micrographs were observed to visualize the consequence of initial corrosion attack. Thereafter, weight losses and conductivity variations of the samples were determined at various time intervals up to 30 days exposure. Weight loss and corrosion rate were calculated according to the following equations respectively [29].

Weight loss of metal was calculated with equation 1 :

$$
\Delta \mathrm{W}=\frac{\left(\mathrm{W}_{\mathrm{o}}-\mathrm{W}_{\mathrm{f}}\right)}{\mathrm{A}}
$$

Corrosion rate was calculate with equation 2:

$$
\mathrm{R}_{\text {corrosion }}=\frac{(\mathrm{K} \times \Delta \mathrm{W})}{(\rho \times \mathrm{T})}
$$

Where:

$\Delta \mathrm{W}=$ Weight loss per exposed surface area $\left(\mathrm{gm} / \mathrm{cm}^{2}\right)$; 
$\mathrm{W}_{\mathrm{o}}=$ Initial weight $(\mathrm{gm})$;

$\mathrm{W}_{\mathrm{f}}=$ Weight after designated period $(\mathrm{gm})$;

$\mathrm{A}=$ Exposed surface area $\left(\mathrm{cm}^{2}\right)$;

$\mathrm{R}_{\text {corrosion }}=$ Corrosion Rate $(\mathrm{mm} /$ year);

$\mathrm{K}=$ Unit conversion factor ;

$\rho=$ Density of metal $\left(\mathrm{gm} / \mathrm{cm}^{3}\right)$;

$\mathrm{T}=$ Exposed time (hour ).

On completion of 30 days immersion, microstructures were observed again for all samples using OEM. In addition, for the samples exposed to two extreme solutions ( $\mathrm{pH} 1$ and $\mathrm{pH} 13$ ), field emission scanning electronic microscope (FE-SEM) images as well as SEM coupled energy dispersive X-ray (EDX) were observed to investigate the effect of corrosion on the surfaces of the samples at the corresponding medium.

\section{Results and Discussion}

\section{Gravimetric Analysis}

In chemical terms, copper is demarcated in the noble metal family and considered as highly resistant to corrosion and oxidation. Copper's resistance to corrosion is attributed mainly to a thin oxide film called patina that forms on the surface of the copper when exposed to a medium. This patina firmly adheres to the outer surface of the copper material and protects the underlying copper layers from further corrosion [7]. However, the water chemistry and other factors cause the medium increasingly aggressive towards copper breaking up the patina to some extent. This phenomenon is comprehensive in the gravimetric analysis of the present experiment. Here, the weight loss per unit exposed surface area $(\Delta \mathrm{W})$ calculated using equation (1) for all four material samples as a function of $\mathrm{pH}$ after immersion for the first day and the first three days are revealed in Fig. 1(a) and 1(b). Both the figures depict that all four materials have shown the maximum weight loss in $\mathrm{pH} 1$ environment amongst the $\mathrm{pH}$ range of 1 to 13 . The highest dissolutions of all three alloying elements $(\mathrm{Cu}, \mathrm{Sn}$ and $\mathrm{Pb})$ present in the four sample materials i.e., material-I, -II, -III and -IV, have occurred at $\mathrm{pH} 1$ with the values of $1.016 \mathrm{gm} / \mathrm{cm}^{2}, 1.282$ $\mathrm{gm} / \mathrm{cm}^{2}, 2.246 \mathrm{gm} / \mathrm{cm}^{2}$ and $1.681 \mathrm{gm} / \mathrm{cm}^{2}$, respectively, after one day and $1.985 \mathrm{gm} / \mathrm{cm}^{2}, 2.972$ $\mathrm{gm} / \mathrm{cm}^{2}, 4.687 \mathrm{gm} / \mathrm{cm}^{2}$ and $3.713 \mathrm{gm} / \mathrm{cm}^{2}$, respectively, after three days due to the surface attack by the aggressive chloride ions of the solution. If the whole $\mathrm{pH}$ range is observed for material-I (pure $\mathrm{Cu}$ ), the weight losses are found to be of least values throughout the $\mathrm{pH}$ range compared to other three copper based materials for the immersion period of one day as well as three days. Material-II (Cu-Sn) has followed the pattern of weight loss curve of material-I with closely higher values over the whole $\mathrm{pH}$ range, and both the curves are looking like bath tab. From the maximum weight loss at $\mathrm{pH} 1$, steady state low weight loss of nearly zero values are observed from $\mathrm{pH} 3$ to $\mathrm{pH} 11$, and thereafter, the curves rise at $\mathrm{pH} 13$ for both material-I and material-II. With the maximum weight losses occurring at $\mathrm{pH} 1$ like material-I and material-II, the weight loss curves of material-III and material-IV have not been found steady; rather, there is a pick at $\mathrm{pH} 5$ due to higher corrosive tendency of $\mathrm{Pb}$ present in both the materials. The weight loss remains low and almost steady from $\mathrm{pH} 7$ to $\mathrm{pH} 11$, and thereafter, the curves have shown the rise at $\mathrm{pH} 13$ making all four curves almost parallel in higher $\mathrm{pH}$ environments. However, the aggressiveness of $\mathrm{NaOH}$ on copper alloy is significantly less than that of $\mathrm{HCl}$ as observed in $\mathrm{pH} 1$ for the immersion period of one day and three days. As a whole, the lowest weight loss occurs for material-I (pure $\mathrm{Cu}$ ), then little higher for materialII (Cu-Sn alloy), further higher for material-IV (Cu-Pb-Sn alloy) and the highest for material-III (Cu$\mathrm{Pb}$ alloy). Therefore, corrosion attacks on the elements are of similar pattern at $\mathrm{pH} 1$ as well as $\mathrm{pH} 13$.

Once the immersion time is increased, the weight loss ascends steadily in the environment of $\mathrm{pH} 1$ for all four material samples. But the weight loss patterns in the environment of $\mathrm{pH} 13$ for all four material samples are quite different. Here, weight loss shows increased trend at the initial stage for all four material samples. For higher immersion period i.e., after few days, the weight 
loss curves have shown a descending trend up to 18 days immersion and have come closer with steady state condition showing no further loss of weight at the end. Therefore, inclusion of Sn or $\mathrm{Pb}$ or solder in copper has not affected badly on the point of corrosion resistance of copper based material while they are immersed in $\mathrm{pH} 13$ environment for prolong period.
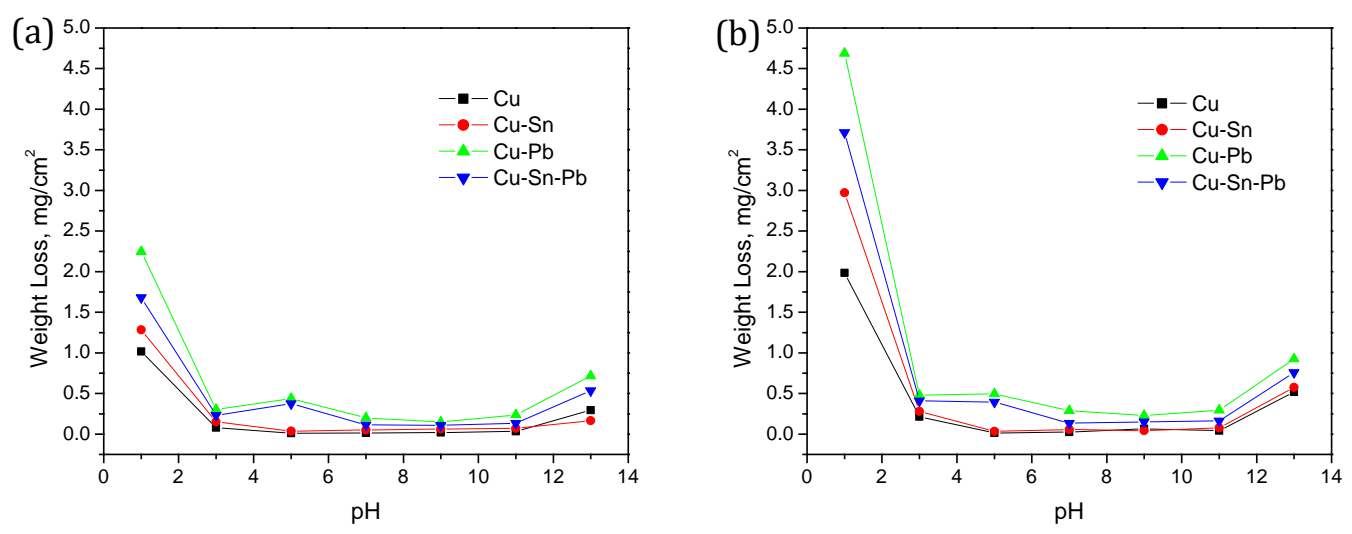

Fig. 1. Weight loss variation as a function of environmental $\mathrm{pH}$ after immersion for (a) 01 day and (b) 03 days

The relative corrosion rates have been calculated from weight-loss tests using equation (2) for the experimental four sample materials at various $\mathrm{pH}$ values after immersion for different time interval up to 30 days. It is found that the corrosion rates are increasing at the initial attack period for each value of $\mathrm{pH}$ ranging from 1 to 13 and reached to the highest pick after 24 hours of immersion. Since fig. 1 indicates that the weight loss rates of all four sample materials are observed as the highest for $\mathrm{pH} 1$ and then the second highest for $\mathrm{pH} 13$, the corrosion rates for these two corresponding $\mathrm{pH}$ environments are presented in fig. 2(a) and 2(b) respectively.
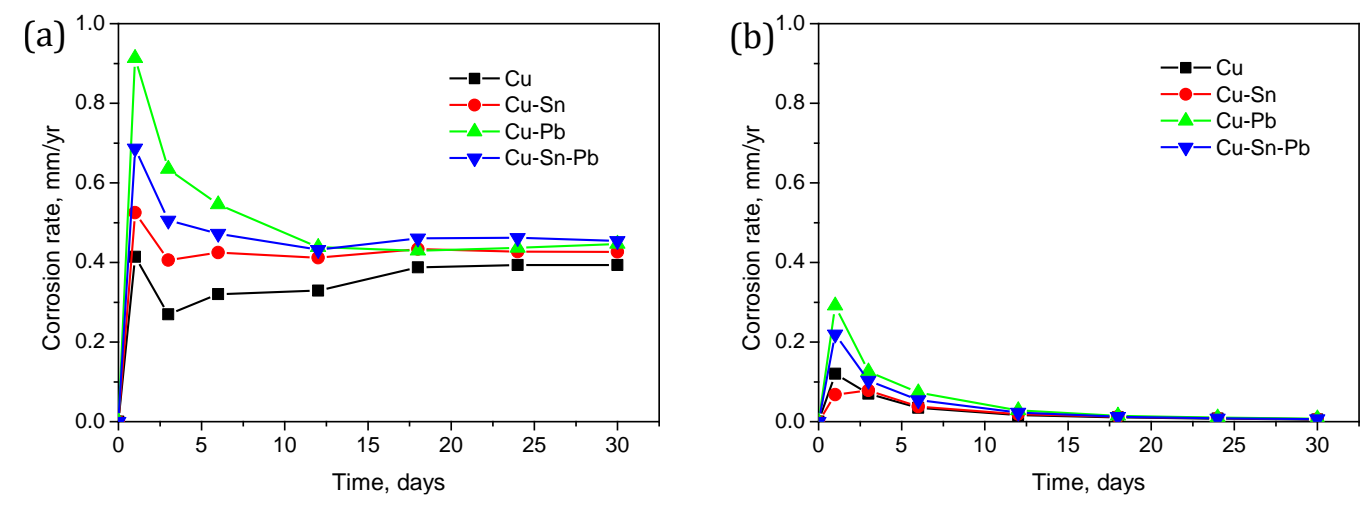

Fig. 2. Corrosion rate variations of sampling materials as a function of time in the environment of (a) $\mathrm{pH} 1$ and (b) $\mathrm{pH} 13$

As shown in fig. 2(a), the highest corrosion rates of all four sample materials for $\mathrm{pH} 1$ environment are observed as $0.4144 \mathrm{~mm} /$ year, $0.525 \mathrm{~mm} / \mathrm{year}, 0.9129 \mathrm{~mm} / \mathrm{year}$ and 0.6868 $\mathrm{mm} /$ year respectively just after immersion of the samples for one day. On the contrary, fig. 2(b) shows that the highest corrosion rates for $\mathrm{pH} 13$ environment are observed for material-I, -III and -IV after one day's immersion and for material-II after 3 days' immersion with the values of $0.1201 \mathrm{~mm} /$ year, $0.2915 \mathrm{~mm} /$ year, $0.2192 \mathrm{~mm} /$ year and $0.0784 \mathrm{~mm} /$ year respectively. Therefore, the lowest peak value of corrosion rate is observed in $\mathrm{pH} 1$ environment for material-I (pure $\mathrm{Cu}$ ) and in pH13 environment for material-II (Cu-Sn). On the contrary, the highest peak value of 
corrosion rate is observed in both environment of $\mathrm{pH} 1$ and $\mathrm{pH} 13$ for material-III which is just $\mathrm{Cu}$ dominated material with only addition $1.9 \% \mathrm{~Pb}$ in it. The material-IV i.e., solder affected copper has shown the peak of intermediate level below material-III, and ultimately, the rate of corrosion in acidic medium is higher due to inclusion of solder materials in copper, whereas the rate is lower in alkaline medium after such inclusion of solder materials in copper. This disproportionate dissolution rate in chloride medium can also be agreed with the researches carried out using electrochemical analysis [27,28].

After prolong immersion period, the corrosion rates are declining for all four sample materials irrespective of $\mathrm{pH}$ values in the solution. The gradual declining trends are culminating to almost zero in all environments after 30 days immersion with an exception to $\mathrm{pH} 1$ where the corrosion rates have been dropped gradually from its peak value, but remained steady for all four materials with the average value of $0.3936 \mathrm{~mm} /$ year, $0.4268 \mathrm{~mm} /$ year, $0.4466 \mathrm{~mm} /$ year and $0.4541 \mathrm{~mm} /$ year, respectively, with little fluctuations as shown in fig. 2(a).

\section{Conductivity Investigation}

The electrical conductivity on the metal surface is generally reduced as an effect of corrosion while the corroded layer remains adhered on the surface [30,31]. But, if the corroded materials are removed, this understanding harvests a question, and how far it is agreeable, has been examined through measuring the conductivity before and after the occurrence of corrosion in the $\mathrm{pH}$ varied environments. Before immersion in the aggressive environment, the original conductivity values of material-I, -II, -III and -IV have been found as $57.61 \mathrm{~S} / \mu \mathrm{m}, 34.72 \mathrm{~S} / \mu \mathrm{m}$, $54.19 \mathrm{~S} / \mu \mathrm{m}$ and $27.64 \mathrm{~S} / \mu \mathrm{m}$ respectively. After the immersion in the solutions of varied $\mathrm{pH}$ environments, the conductivity values of the four sample materials have been found on average as $57.373 \mathrm{~S} / \mu \mathrm{m}, 35.941 \mathrm{~S} / \mu \mathrm{m}, 54.453 \mathrm{~S} / \mu \mathrm{m}$ and $27.966 \mathrm{~S} / \mu \mathrm{m}$ respectively for one day, and $58.006 \mathrm{~S} / \mu \mathrm{m}, 35.697 \mathrm{~S} / \mu \mathrm{m}, 55.719 \mathrm{~S} / \mu \mathrm{m}$ and $28.463 \mathrm{~S} / \mu \mathrm{m}$ respectively after three days, which are very close to their corresponding original values. Fig. 3 indicates that the conductivity values have not been harshly affected by the environments of wide $\mathrm{pH}$ range from 1 to 13 after the immersion of samples for one day and three days.
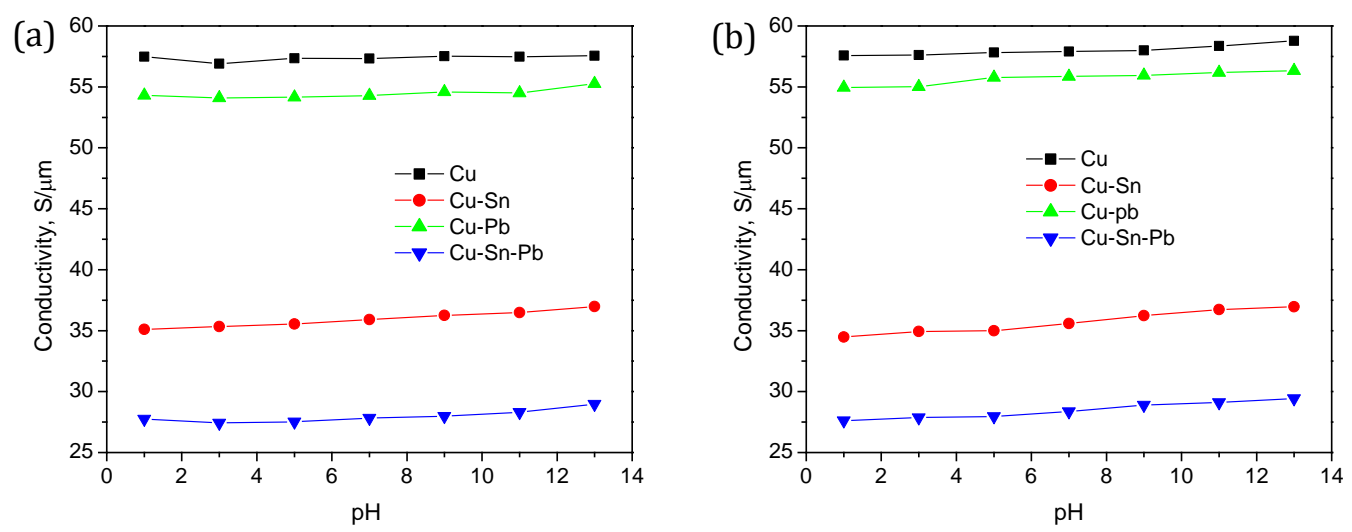

Fig. 3. Conductivity variations of four sampling materials as a function of environmental $\mathrm{pH}$ after immersion for: (a) 01 day and (b) 03 days

However, there are little variations in conductivity values with respect to $\mathrm{pH}$ values of the solutions for both the immersion period of the samples. The ranges of such fluctuations for one day immersion, i.e., minimum to maximum values for material-I, -II, -III and -IV are 56.911 to $57.561 \mathrm{~S} / \mu \mathrm{m}, 35.097$ to $36.969 \mathrm{~S} / \mu \mathrm{m}, 54.096$ to $55.261 \mathrm{~S} / \mu \mathrm{m}$ and 27.418 to $28.974 \mathrm{~S} / \mu \mathrm{m}$ respectively, resulting the corresponding standard deviations of $0.222 \mathrm{~S} / \mu \mathrm{m}, 0.669 \mathrm{~S} / \mu \mathrm{m}, 0.396$ $\mathrm{S} / \mu \mathrm{m}$ and $0.531 \mathrm{~S} / \mu \mathrm{m}$. The conductivity values have been found to be of little higher with the 
increase of $\mathrm{pH}$ values. This phenomenon is considered to be the result of pit formation and diffusion of aggressive ions leading to porosity on the surface at irregular forms occurring in lower $\mathrm{pH}$ solution in contrast to thin films of copper oxide and hydroxide in the solution of higher $\mathrm{pH}$ solution. Moreover, anodic polarization of copper may result in anodic dissolution or film formation depending on $\mathrm{pH}$ value of the solution.
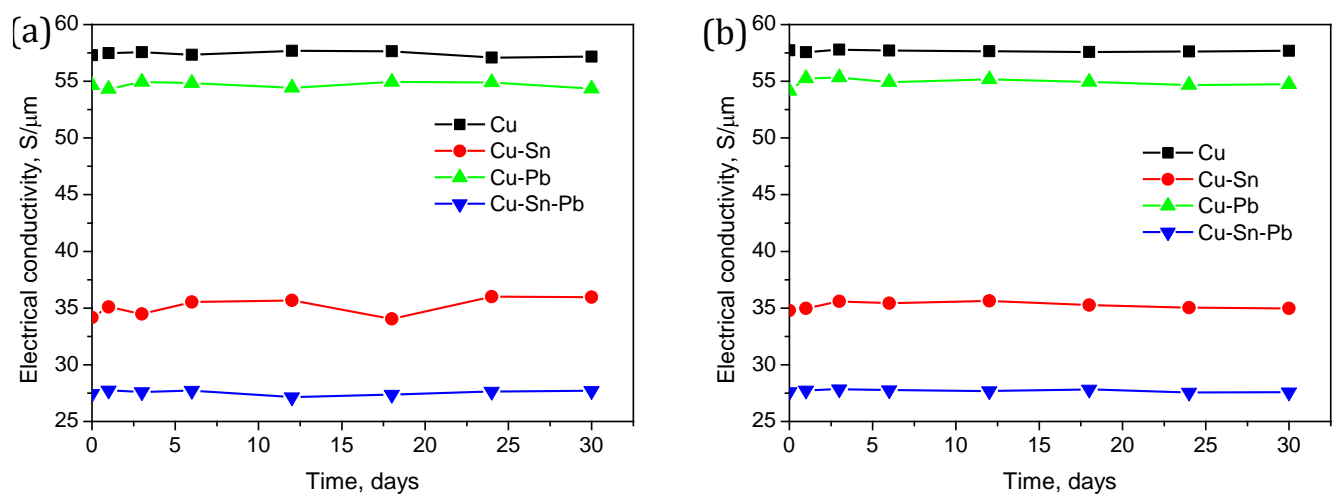

Fig. 4. Conductivity variations of four sampling materials as a function of time in the environment of: (a) $\mathrm{pH} 1$ and (b) $\mathrm{pH} 13$

The conductivity variations over immersion periods are not also significant. The fluctuations are somehow observed at the initial period of immersion. After immersion for 3 days and onwards, fluctuations are found very minimal and at the end level of 30 days observation the conductivity values are found to be quiet steady as shown in fig. 4 for the environment of $\mathrm{pH} 1$ and $\mathrm{pH} 13$.

\section{Microstructure Observation}

The OEM images of all four sample materials as cast condition and after submersion for 30 days are observed in different $\mathrm{pH}$ environment. Amongst them, micrographs of corroded samples in $\mathrm{pH} 1$ and $\mathrm{pH} 13$ environments along with uncorroded samples are presented by rows in fig. 5. The topmost row shows the micrographs of sample materials as cast condition, where fresh polishing marks are visible without any foreign particles in the grain boundaries. The microstructure of the as-cast alloy consists of $\alpha$-phase, which is a face centric cubic copper, and little dark $\beta$-phase, which is martensitic and intermetallic particles. Thus the main visible feature is the granular structure of pure copper with equiaxial grains in random orientations. After 30 days immersion in $\mathrm{pH}$ varied environments, the martensitic areas have appeared as dark, which indicates that it has been attacked preferentially. The micrographs also indicate less attack on $\alpha-$ phase areas. The effect of $\mathrm{pH}$ value can be differentiated through the presence of dark $\beta$-phase. Hence, there has been a change of stacking sequence in the grains through the twinning mechanism. The micrographs for $\mathrm{pH} 1$ solution have been found to be the darkest amongst all environments and for $\mathrm{pH} 13$ the second darkest, which confirm the highest and the second highest corrosion rates respectively as observed through gravimetric analysis.

The microstructures of corroded samples after 30 days immersion in different $\mathrm{pH}$ environments have also been observed using SEM and Few of such SEM images along with EDX spectra are presented in figures 6 and 7 for the environments of $\mathrm{pH} 1$ and $\mathrm{pH} 13$, respectively. These figures indicate some pits in all four sample materials with randomly nucleated orientation; demonstrating that the samples have suffered from pitting corrosion attack. It is considered that the pits are formed either by intermetallic dropping out from the surface due to the dissolution of the surrounding matrix or selective dissolutions of the intermetallics or particles during immersion period. Moreover, the pits are found to be more prominent for $\mathrm{pH} 13$ environment than those of $\mathrm{pH} 1$ 
environment. It may be perplexing with the gravimetric analysis results, where corrosion rates have been found more for $\mathrm{pH} 1$ environment than those of $\mathrm{pH} 13$.

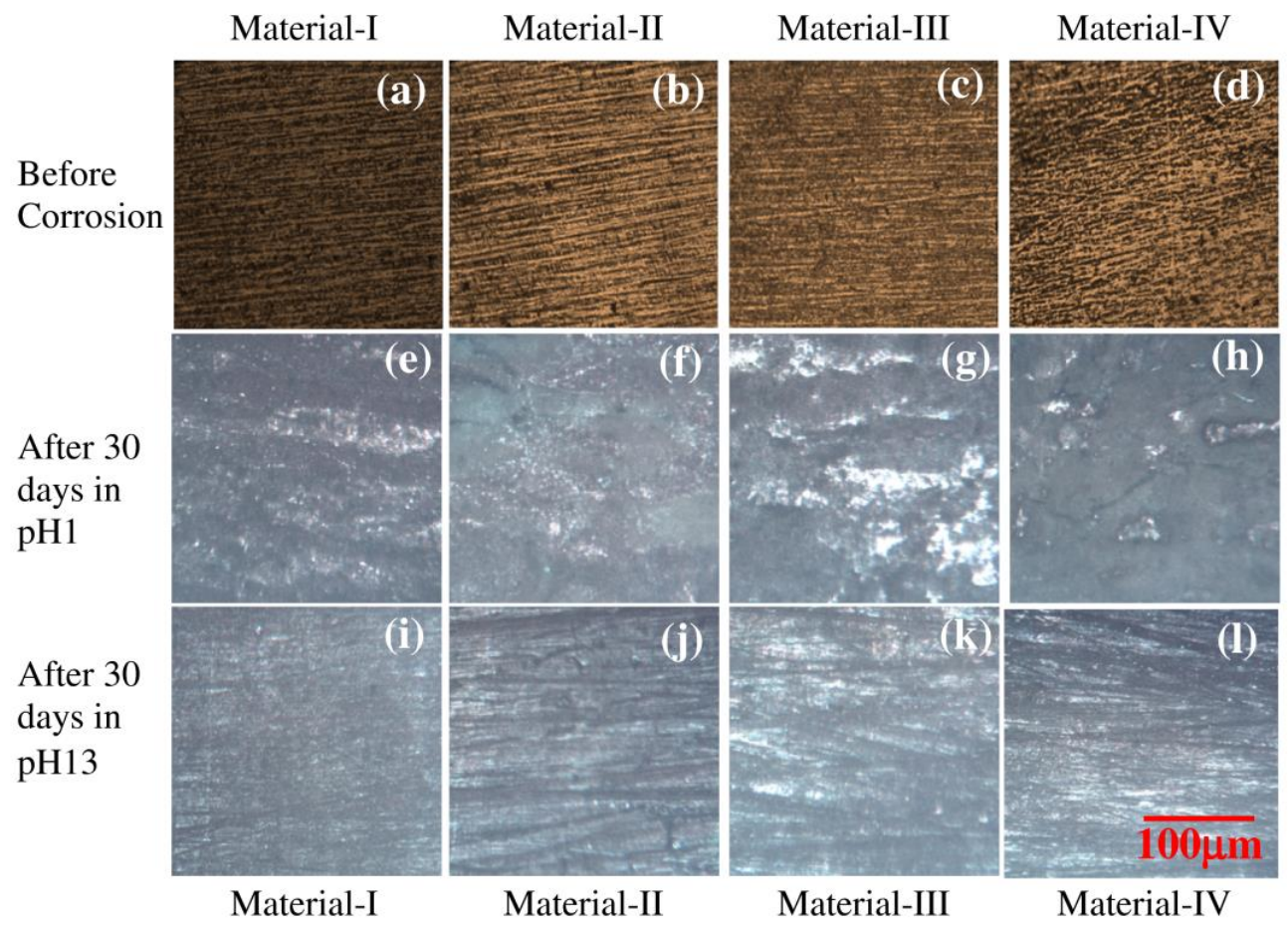

Fig. 5. Microstructure of alloys with the magnification factor of 300x: (a) Material-I before corrosion, (b) Material-II before corrosion, (c) Material-III before corrosion, (d) Material-IV before corrosion, (e) Material-I after 30 days in pH1, (f) Material-II after 30 days in pH1, (g) Material-III after 30 days in pH1, (h) Material-IV after 30 days in pH1, (i) Material-I after 30 days in pH13, (j) Material-II after 30 days in pH13, (k) Material-III after 30 days in pH13, (1) Material-IV after 30 days in $\mathrm{pH} 13$

However, if EDX spectra are noticed, significant insertion of chlorine is observed in the samples by 30 days immersion in $\mathrm{pH} 1$ environment in addition to the inclusion of carbon and oxygen. On the other hand in pH13 environment, inclusion of only carbon and oxygen has been observed in the samples after the immersion period of 30 days. Basically, the insertion of chlorine i.e. chloride formation has played pivoting role for higher corrosion rate in the environment of $\mathrm{pH} 1$ than that of $\mathrm{pH} 13$. Moreover, EDX spectra indicate more oxygen for $\mathrm{pH} 13$ solution due to higher amount of oxide formation than that of $\mathrm{pH}$. As such pouring marks on SEM images are also more for $\mathrm{pH} 1$ solution than that of $\mathrm{pH} 13$ solution, and thus pits are not prominently observed on samples immersed in $\mathrm{pH} 1$ solution as compared to $\mathrm{pH} 13$ solution. 

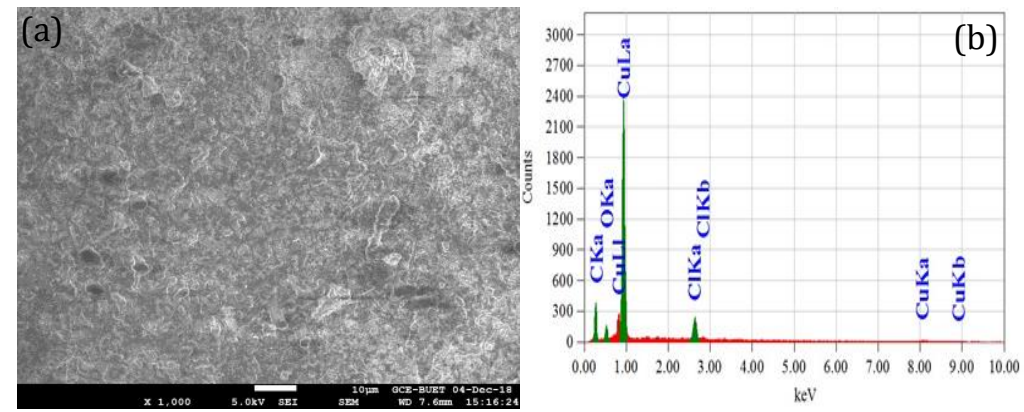

Weight percentage C 31.98, O 5.22, Cl 6.36, Cu 56.44
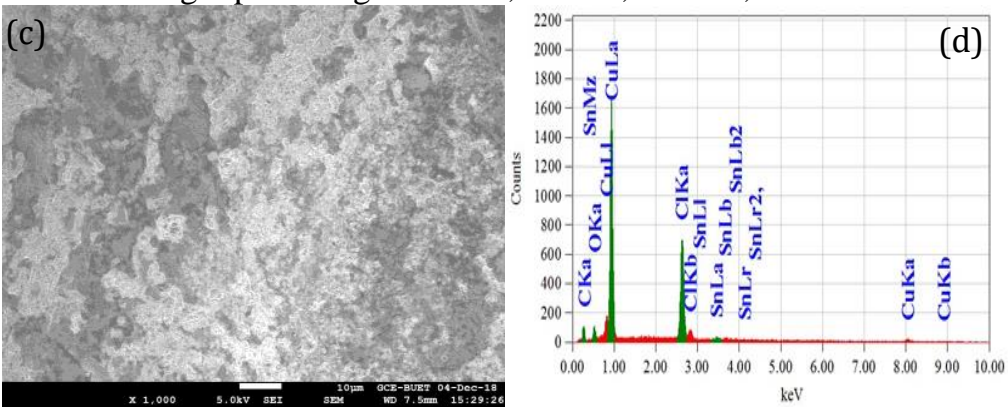

Weight percentage C 18.37, O 4.39, Cl 27.47, Cu 47.14, Sn 2.63
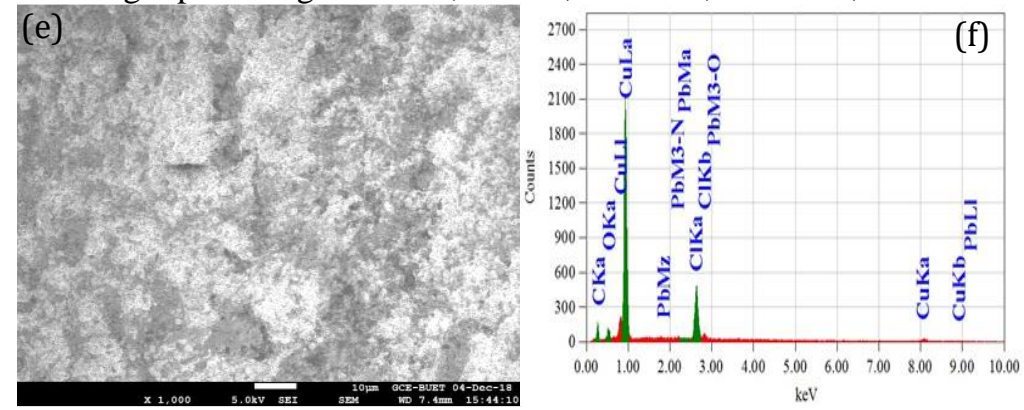

Weight percentage $\mathrm{C} 17.89, \mathrm{O} 4.03, \mathrm{Cl} 16.27, \mathrm{Cu} 60.62, \mathrm{~Pb} 1.18$
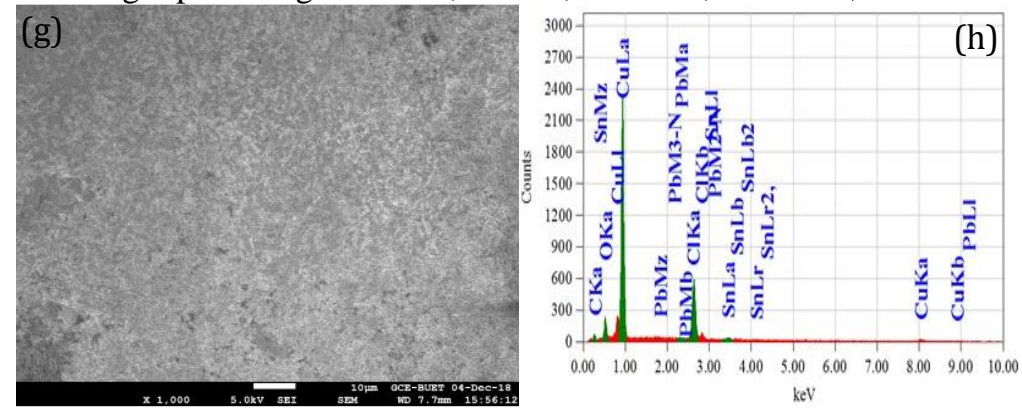

Weight percentage C 6.73, O 7.47, $\mathrm{Cl} 19.27, \mathrm{Cu} 62.83, \mathrm{Sn} 2.81, \mathrm{~Pb} .89$

Fig. 6. SEM images and EDX spectra after exposure in pH1 solution for 30 days: (a) SEM of Material-I, (b) EDX of Material-I, (c) SEM of Material-II, (d) EDX of Material-II, (e) SEM of Material-III, (f) EDX of Material-III, (g) SEM of Material-IV and (h) EDX of Material-IV 

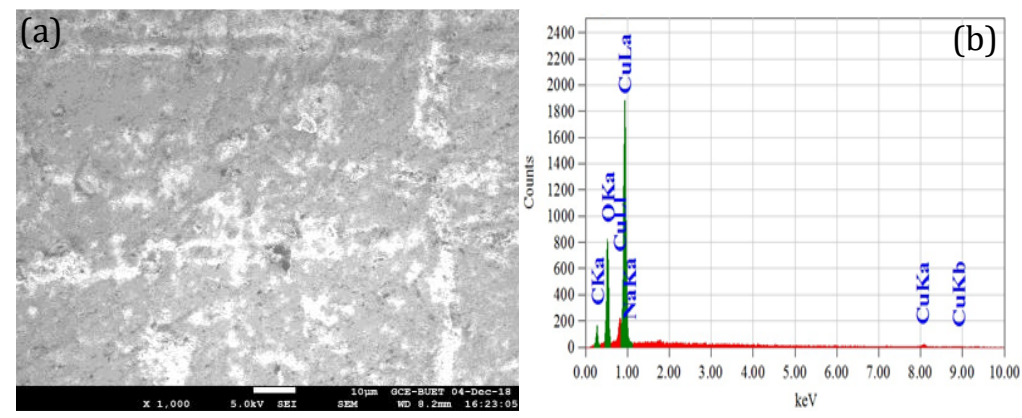

Weight percentage C $11.58, \mathrm{O} 28.06, \mathrm{Cu} 60.36$
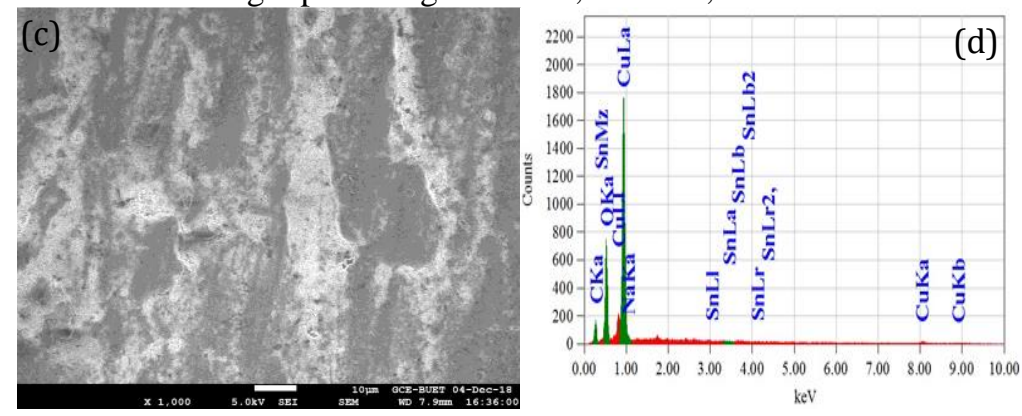

Weight percentage C 13.71, O 26.28, Cu 58.76, Sn 1.25
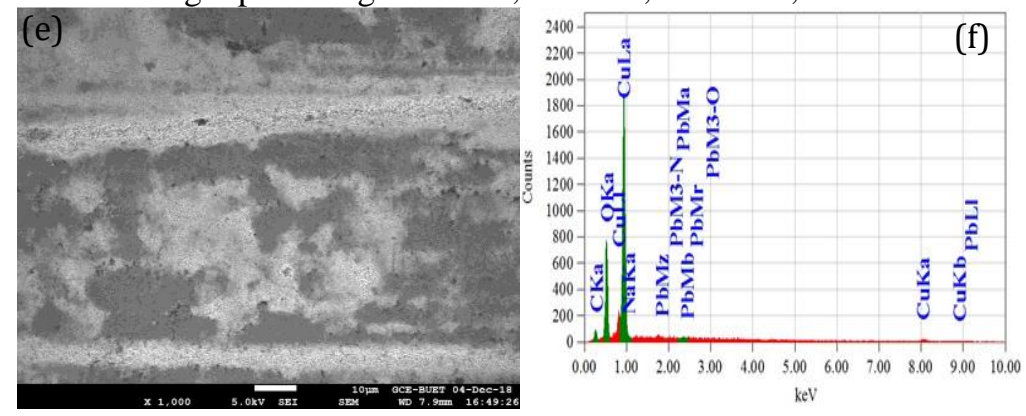

Weight percentage $\mathrm{C} 6.71, \mathrm{O} 26.64, \mathrm{Cu} 65.07, \mathrm{~Pb} 1.58$
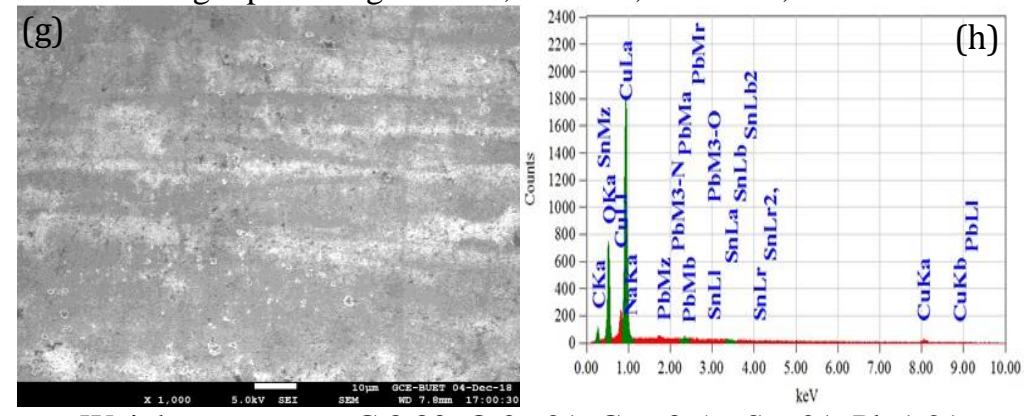

Weight percentage C 8.80, O 26.21, Cu 63.56, Sn .21, Pb 1.21

Fig. 7. SEM images and EDX spectra after exposure in pH13 solution for 30 days: (a) SEM of Material-I, (b) EDX of Material-I, (c) SEM of Material-II, (d) EDX of Material-II, (e) SEM of Material-III, (f) EDX of Material-III, (g) SEM of Material-IV and (h) EDX of Material-IV

In overall consideration, high uniform global corrosion rate values are obtained for $\mathrm{pH} 1$ than that of $\mathrm{pH} 13$ in contrast to the formation of pits. Here, the variations of oxide and chloride 
contents for four sample materials are not such significant, but surface images indicate the corrosion rates are quite different for all four sample materials.

\section{Conclusions}

The notable findings of the present experimental investigations can be summarized as follows:

The corrosion immunity levels of work hardened copper materials are affected marginally in $\mathrm{pH}$ varied environments. However, $\mathrm{pH} 1$ solution has been found to be the highest corrosive environment and the next is the $\mathrm{pH} 13$ solution for all four copper based sample materials.

Overall leaching losses have been found to be increased for addition of $\mathrm{Sn}$ and/or $\mathrm{Pb}$ in $\mathrm{Cu}$ for each $\mathrm{pH}$ value. The highest loss is found to be of $\mathrm{Cu}-\mathrm{Pb}$ alloy amongst four sample materials. $\mathrm{Cu}-\mathrm{Pb}$ alloy is followed by $\mathrm{SnPb}$-solder affected copper, then $\mathrm{Cu}-\mathrm{Sn}$ alloy and the lowest loss is of pure copper. It indicates that alloying of copper with tin or lead has reduced its corrosion resistance especially in acidic environment.

Corrosion rates of all four sample materials have been found to be the highest by the first immersion period, and then their rates have come down to the steady values for all $\mathrm{pH}$ varied environments. After 30 days of immersion, the corrosion rates for all four sample materials have been found to be close to zero with the exception of $\mathrm{pH} 1$ environment.

The conductivity values of sample materials have not been significantly affected over the immersion period. However, there have been little fluctuations in conductivity values due to corroded surface and pit formations.

The microstructures of the corroded surfaces observed through OEM and SEM images have confirmed the highest surface corrosion in $\mathrm{pH} 1$ solution amongst all environments.

\section{References}

[1] J.R. Davis (Eds), Copper and Copper Alloys, ASM Specialty Handbook Series, ASM International, Materials Park, Ohio 44073-0002, USA, 2001.

[2] L. Collini (Ed), Copper Alloys - Early Applications and Current Performance - Enhancing Processes, InTech Janeza Trdine 9, 51000 Rijeka, Croatia, 2012.

[3] M. Villena, F. Greve, On resource depletion and productivity: The case of the Chilean copper industry. Resources Policy. 2018. doi:10.1016/j.resourpol.2018.10.001

[4] J. Cui, E. Forssberg, Mechanical recycling of waste electric and electronic equipment: a review, Journal of Hazardous Materials, 99(3), 2003, pp. 243-263. doi:10.1016/s03043894(03)00061-x

[5] S. Fogarasi, F. Imre-Lucaci, A. Imre-Lucaci, P. Ilea, Copper recovery and gold enrichment from waste printed circuit boards by mediated electrochemical oxidation, Journal of Hazardous Materials, 273, 2014, pp. 215-221. doi:10.1016/ j.jhazmat.2014.03.043

[6] C. Samuelsson, B. Björkman, Copper Recycling, Handbook of Recycling, 2014, pp. 8594. doi:10.1016/b978-0-12-396459-5.00007-6

[7] T. E. Graedel, K. Nassau, J. P. Franey, Copper patinas formed in the atmosphere-I. Introduction, Corrosion Science, 27(7), 1987, 639-657. doi:10.1016/0010938x(87)90047-3

[8] C. Leygraf, T. Chang, G. Herting, I. O. Wallinder, The Origin and Evolution of Copper Patina Colour, Corrosion Science, 157, 2019, pp. 337-346. doi:10.1016/ j.corsci.2019.05.025

[9] S. D. Cramer, B. S. Covino, Corrosion: Materials. ASM Handbook, Volume 13B, ASM International. Materials Park, Ohio 44073-0002 USA, 2005, p125. 
[10] G. Hultquist, G. K. Chuah, K. L. Tan, Comments on hydrogen evolution from the corrosion of pure copper, Corrosion Science, 29(11-12), 1989, pp. 1371-1377. doi:10.1016/0010938x(89)90125-x

[11] P. Szakálos, G. Hultquist, G. Wikmark, Corrosion of Copper by Water, Electrochemical and Solid-State Letters, 10(11), 2007, pp. C63-C67. doi: 10.1149/ 1.2772085

[12] G. Hultquist, P. Szakálos, M. J. Graham, G. I. Sproule, G. Wikmark, Detection of hydrogen in corrosion of copper in pure water, Paper no $3884, \mathbf{1 7}^{\text {th }}$ International Corrosion Congress, NACE International, USA, 2008.

[13] G. Hultquist, P. Szakálos, M. J. Graham, A. B. Belonoshko, G. I. Sproule, L. Gråsjö, A. Rosengren, Water Corrodes Copper, Springer, Catalysis Letters, 132(3-4), 2009, pp. 311316. doi:10.1007/s10562-009-0113-x

[14] G. Hultquist, M. J. Graham, P. Szakalos, G. I. Sproule, A. Rosengren, L. Gråsjö, (2011). Hydrogen gas production during corrosion of copper by water. Corrosion Science, 53(1), 2011, pp. 310-319. doi:10.1016/j.corsci.2010.09.037

[15] G. Hultquist, Why copper may be able to corrode in pure water, Corrosion Science, 93, 2015, pp. 327-329. doi:10.1016/j.corsci.2015.01.002

[16] G. Hultquist, M. J. Graham, O. Kodra, S. Moisa, R. Liu, U. Bexell, J. L. Smialek, Corrosion of copper in distilled water without $\mathrm{O} 2$ and the detection of produced hydrogen. Corrosion Science, 95, 2015, pp. 162-167. doi:10.1016/j.corsci.2015.03.009

[17] J. P. Simpson, R. Schenk, Hydrogen evolution from corrosion of pure copper, Corrosion Science, 27(12), 1987, pp. 1365-1370. doi:10.1016/0010-938x(87)90131-4

[18] A. Hedin, A. J. Johansson, C. Lilja, M. Boman, P. Berastegui, R. Berger, M. Ottosson, Corrosion of copper in pure $O 2$-free water? Corrosion Science, 137, 2018, pp. 112. doi:10.1016/j.corsci.2018.02.008

[19] Y. Wan, X. Wang, H. Sun, Y. Li, K. Zhang, Y. Wu, Corrosion Behavior of Copper at Elevated Temperature, Int. J. Electrochem. Sci., 7, 2012, pp. 7902 - 7914.

[20] H. Li, A. Shi, M. Li, X. Zhang, Effect of pH, Temperature, Dissolved Oxygen, and Flow Rate of Overlying Water on Heavy Metals Release from Storm Sewer Sediments, Hindawi Publishing Corporation, Journal of Chemistry, Article ID 434012, 2013. doi.org/10.1155/2013/434012

[21] F. Arjmand, A. Adriaens, Influence of $\mathrm{pH}$ and Chloride Concentration on the Corrosion Behavior of Unalloyed Copper in NaCl Solution: A Comparative Study Between the Micro and Macro Scales, Materials 5, 2012, pp. 2439-2464. doi:10.3390/ma5122439

[22] A. S. Medhat, H. H. Abdel-Rahman, Corrosion of Copper Metal in Presence of Binary Mixtures, American Journal of Applied Sciences 4 (8), 2007, pp. 554-564.

[23] B. Kuznicka, K. Junik, Intergranular stress corrosion cracking of copper - A case study, Corrosion Science 49, 2007, pp. 3905-3916. doi:10.1016/j.corsci.2007.05.014

[24] Y.N. Zhang, J.L. Zi, M.S. Zheng, J.W. Zhu, Corrosion behavior of copper with minor alloying addition in chloride solution, Journal of Alloys and Compounds 462, 2008, pp. 240-243. doi:10.1016/j.jallcom.2007.08.008

[25] C. Craciunescu, A. S. Hamdy, The Effect of Copper Alloying Element on the Corrosion Characteristics of Ti-Ni and Ternary Ni-Ti-Cu Meltspun Shape Memory Alloy Ribbons in 0.9\% NaCl Solution, Int. J. Electrochem. Sci., 8, 2013, 10320 - 10334.

[26] A. Robin, G. A. S. Martinez, P. A. Suzuki, Effect of cold-working process on corrosion behavior of copper, Materials and Design 34, 2012, pp. 319-324. doi: 10.1016/j.matdes.2011.08.018 
[27] M. M. Al-Abdallah, A.K. Maayta, M.A. Al-Qudah and N.A.F. Al-Rawashdeh, Corrosion Behavior of Copper in Chloride Media, The Open Corrosion Journal, 2, 2009, pp. 71-76. doi:10.1016/j.matdes.2008.10.015

[28] M. A. Fusco , C. J. Oldham, G. N. Parsons, Investigation of the Corrosion Behavior of Atomic Layer Deposited Al2O3/TiO2 Nanolaminate Thin Films on Copper in $0.1 \mathrm{M} \mathrm{NaCl}$, Materials 12, 672, 2019. doi:10.3390/ma12040672

[29] R. Baboian, Corrosion Tests and Standards - Application and Interpretation. ASTM International, Philadelphia, USA, 2005, pp. 23-24.

[30] M. A. M. Sabri, A. B. Sulong, F. K. Chin, J. Sahari, Effect of Corrosion on the Electrical Conductivity of Metals and Polymer Composite, Jurnal Teknologi (Sciences \& Engineering) 59, Suppl 2, 2012, pp. 81-85.

[31] J. Song, L. Wang, A. Zibart, C. Koch, Corrosion Protection of Electrically Conductive Surfaces, Metals, 2, 2012, 450-477. doi:10.3390/met2040450.

Received: May 05, 2020

Accepted: September 18, 2020 